\title{
Intermittent pressure augmentation during retrograde cerebral perfusion under moderate hypothermia provides adequate neuroprotection: An experimental study
}

Mitsuhiro Kawata, MD, Shinichi Takamoto, MD, PhD, Kazuo Kitahori, MD, PhD, Hiroyuki Tsukihara, MD, Tetsuro Morota, MD, PhD, Minoru Ono, MD, PhD, Noboru Motomura, MD, PhD, Arata Murakami, MD, PhD, and Yoshihiro Suematsu, MD, PhD

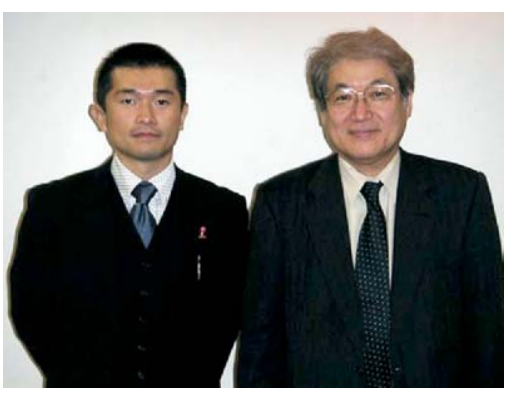

Drs Kawata and Takamoto (left to right)

Objective: For cerebral protection during aortic surgery, we introduced a novel retrograde cerebral perfusion method with intermittent pressure augmentation. We then assessed whether this novel method provides benefits similar to those provided by antegrade selective cerebral perfusion.

Methods: Eighteen dogs were randomly divided into 3 groups: the RCP-INT group, intermittent-retrograde cerebral perfusion at $15 \mathrm{~mm} \mathrm{Hg}$ with intermittent pressure augmentation to $45 \mathrm{~mm} \mathrm{Hg}(\mathrm{n}=6)$; the ASCP group, antegrade selective cerebral perfusion at a flow rate of $10 \mathrm{~mL} \cdot \mathrm{kg}^{-1} \cdot \min ^{-1}(\mathrm{n}=6)$; and the sham group, no circulatory arrest $(n=6)$. Cooling $\left(26^{\circ} \mathrm{C}\right)$ with cardiopulmonary bypass and 60 minutes of circulatory arrest were performed in the RCP-INT and ASCP groups. The levels of tau protein in the cerebrospinal fluid and the diameters of the retinal vessels were measured. The neurologic deficit scores and the histopathologic damage scores of the brains were determined.

Results: The total postoperative tau protein levels (calculated as the area under the curve) did not differ significantly between the RCP-INT and ASCP groups (203 \pm $87 \mathrm{pg} \cdot \mathrm{mL}^{-1} \cdot \mathrm{h}$ vs $\left.154 \pm 69 \mathrm{pg} \cdot \mathrm{mL}^{-1} \cdot \mathrm{h}, P=.95\right)$. The retinal vessels were effectively dilated at an augmented pressure of $45 \mathrm{~mm} \mathrm{Hg}$ in the RCP-INT group. The total neurologic deficit score $(0=$ normal, $500=$ brain death $)$ and histopathologic damage score $(0=$ normal, $40=$ worst $)$ were not significantly different between the RCP-INT and ASCP groups (neurologic deficit score: $75 \pm 21$ vs $70 \pm 21, P=.98$; histopathologic damage score: $13.5 \pm 1.5$ vs $14.2 \pm 1.3, P=.84$ ).

Conclusions: Intermittent augmented pressure dilated the cerebral vessels, allowing adequate blood supply without injuring the brain. This retrograde cerebral perfusion method provides adequate neuroprotection during moderate hypothermia.

From the Department of Cardiothoracic Surgery, Graduate School of Medicine, University of Tokyo, Tokyo, Japan.

Received for publication June 21, 2005; revisions received Dec 27, 2005; accepted for publication Jan 10, 2006.

Address for reprints: Mitsuhiro Kawata, MD, Department of Cardiothoracic Surgery, Graduate School of Medicine, University of Tokyo, 7-3-1 Hongo, Bunkyo-ku, Tokyo 113-8655, Japan (E-mail: mkawataths@umin.ac.jp).

J Thorac Cardiovasc Surg 2006;132:80-8

$0022-5223 / \$ 32.00$

Copyright $(\odot) 2006$ by The American Association for Thoracic Surgery

doi:10.1016/j.jtcvs.2006.01.060
$\mathrm{W}$ e introduced a novel retrograde cerebral perfusion (RCP) method with intermittent pressure augmentation for cerebral protection during aortic surgery. The neuroprotective efficacy of this method, as compared with that of the conventional method, has been confirmed by our institution. ${ }^{1}$ Intermittent augmented pressure effectively dilates cerebral vessels, allowing adequate blood supply to the brain while minimizing brain damage. In this study we examined whether this novel method could provide similar clinical benefits to those provided by antegrade selective cerebral perfusion (ASCP) during moderate hypothermia.

\section{Materials and Methods}

\section{Animal Care}

This study was approved by the Animal Care and Use Committee of the University of Tokyo. All the animals were acclimatized in the Section of Animal Research of the Center for Disease 


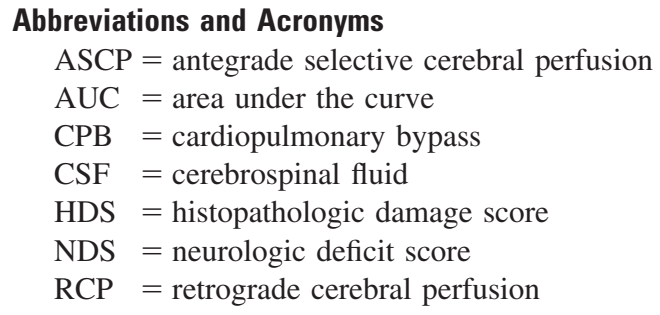

Biology and Integrative Medicine. All received humane care in compliance with the 1996 "Guide for the care and use of laboratory animals" (1996 Institute for Laboratory Animal Research).

\section{Experimental Groups}

Eighteen adult mongrel dogs, each weighing 23 to $32.1 \mathrm{~kg}$ (mean, $28.7 \mathrm{~kg}$ ) were randomly divided into the following 3 groups: the RCP-INT group, RCP through both maxillary veins at a baseline pressure of $15 \mathrm{~mm} \mathrm{Hg}$ with intermittent pressure augmentation every 30 seconds to $45 \mathrm{~mm} \mathrm{Hg}$ by only increasing the flow of the pump manually $(n=6)$; the ASCP group, ASCP at a flow rate of $10 \mathrm{~mL} \cdot \mathrm{kg}^{-1} \cdot \mathrm{min}^{-1}$ through an arterial cannula in the ascending aorta after clamping of the proximal ascending aorta, left subclavian artery, and descending aorta $(n=6)$; and the sham group, no circulatory arrest $(n=6)$.

\section{Animal Preparation}

All animals were premedicated with ketamine hydrochloride (10 $\mathrm{mg} / \mathrm{kg}$ administered intramuscularly) and anesthetized and maintained with sodium pentobarbital throughout the operation. Support with a pressure-controlled ventilator (Bird Mark-7 respirator; Bird Products Corp, Viasys Healthcare Inc, Palm Springs, Calif) was started at $100 \%$ oxygen after endotracheal intubation. A partial laminectomy at the level of the first lumbar vertebra was performed, and a 20-gauge catheter was inserted into the external cerebrospinal fluid (CSF) space toward the cranial side to allow continuous pressure monitoring of the CSF and sampling at several time points. The femoral artery and the external jugular vein were cannulated with 20 -gauge catheters for blood sampling, and the arterial and central venous pressures were monitored continuously. In the RCP-INT group two 16-gauge cannulas were inserted into each of the maxillary veins of either side; these cannulas were used only during RCP. Blood samples were analyzed after correction for the animal's body temperature. Oxygen saturation, $\mathrm{pH}$, oxygen tension, carbon dioxide tension, base excess, carbonic acid, electrolytes, and hemoglobin levels were measured with a blood gas analyzer (ABL505, Radiometer Medical Aps, Copenhagen, Denmark) and a hemoglobin and oxygen saturation analyzer (OMS2 Hemoximeter, Radiometer Medical Aps). The core temperature of the animals was monitored by using probes in the esophagus and rectum.

\section{Experimental Protocol}

Before systemic heparinization, $400 \mathrm{~mL}$ of blood was removed for hemodilutional autologous transfusion. A median sternotomy was performed. After systemic heparinization (300 IU/kg), a 16F arterial cannula (Medtronic, Inc, Minneapolis, Minn) was inserted in
TABLE 1. A. Criteria for neurologic deficit score

\begin{tabular}{lccc}
\hline A. Central nerve function & & & \\
Variable & Normal & Weak & Absent \\
Light reflex & 0 & 5 & 20 \\
Lid reflex & 0 & 5 & 20 \\
$\quad$ Corneal reflex & 0 & 5 & 20 \\
Auditory reflex & 0 & 5 & 20 \\
$\quad$ Carinal reflex & 0 & 5 & 20 \\
B. Respiration condition & & & \\
Normal & 0 & & \\
Hyperventilation & 25 & & \\
Abnormal & 50 & & \\
Apnea & 100 & & \\
C. Motor and sensory function & & & \\
Variable & Normal & Weak & Absent \\
Movement of limbs & 0 & 20 & 50 \\
Motor response to pain & 0 & 20 & 50 \\
D. Level of consciousness & & & \\
Normal & 0 & & \\
Cloudy & 30 & & \\
Delirium & 45 & \\
Stupor & 60 & \\
Coma & 100 & \\
E. Abnormality & & \\
No convulsion & 0 & \\
Temporal convulsion & 50 & \\
Serial recurrent convulsion & 100 & & \\
\hline & &
\end{tabular}

Total $=$ sum of all sections. Best possible total neurologic deficit score $=$ 0 ; worst possible total neurologic deficit score $=500$.

the ascending aorta, and a 36F venous single cannula (Terumo Co, Ltd, Tokyo, Japan) was inserted in the right atrium. Extracorporeal circulation was performed with a membrane oxygenator (Capiox SX, Terumo Co, Ltd) and an extracorporeal pump (MHS-15-IV, MERA; Senko Medical Instrument Mfg, Co, Ltd, Tokyo, Japan) containing a circuit primed with a hemodilute solution of $800 \mathrm{~mL}$ of lactated Ringer's solution, $50 \mathrm{~mL}$ of $20 \%$ human albumin, 40 $\mathrm{mL}$ of sodium bicarbonate, $200 \mathrm{~mL}$ of mannitol, and $5000 \mathrm{IU}$ of heparin. Cardiopulmonary bypass (CPB) was established at a flow rate of $100 \mathrm{~mL} \cdot \mathrm{kg}^{-1} \cdot \min ^{-1}$, with the flow adjusted to maintain a mixed venous oxygen saturation of approximately $75 \%$. A 14-gauge catheter was inserted into the left ventricle from the apex to permit decompression of the left ventricle during CPB. The animals were cooled to $26^{\circ} \mathrm{C}$ (moderate hypothermia) with a heat exchanger. The $\mathrm{pH}$ was maintained at 7.40 by means of $\mathrm{pH}$-stat principles, with an arterial $\mathrm{PaCO}_{2}$ of 35 to $40 \mathrm{~mm} \mathrm{Hg}$, corrected for body temperature. Cardiac arrest was induced by using cold cardioplegic solution after crossclamping of the ascending aorta. Then the animals (except those in the sham group) underwent 60 minutes of circulatory arrest. During the circulatory arrest, brain protection procedures were carried out according to the group definition, as mentioned previously. In the RCP-INT group the arterial cannula in the ascending aorta was opened to maintain the common carotid arterial pressure at atmospheric pressure.

After the period of circulatory arrest, CPB was reestablished. Cardioversion was performed, if necessary, to resume the sinus 
TABLE 1. B. Neurologic deficit score after the operation

\begin{tabular}{|c|c|c|c|c|}
\hline & RCP-INT & ASCP & Sham & $P$ value \\
\hline A. Central nerve function & $2.5 \pm 1.1$ & $3.3 \pm 1.1$ & $3.3 \pm 1.1$ & .82 \\
\hline B. Respiration condition & $8.3 \pm 5.3$ & $8.3 \pm 5.3$ & $8.3 \pm 5.3$ & 1.00 \\
\hline D. Level of consciousness & $20 \pm 6$ & $20 \pm 6$ & $15 \pm 7$ & .82 \\
\hline E. Abnormality & $25 \pm 11$ & $25 \pm 11$ & $17 \pm 11$ & .83 \\
\hline Total & $75 \pm 21$ & $70 \pm 21$ & $57 \pm 23$ & .83 \\
\hline
\end{tabular}

Best possible total neurologic deficit score $=0$; worst possible total neurologic deficit score $=500$. $R C P$-INT, Intermittent-retrograde cerebral perfusion at $15 \mathrm{~mm} \mathrm{Hg}$ with intermittent pressure augmentation to $45 \mathrm{~mm} \mathrm{Hg} ; A S C P$, antegrade selective cerebral perfusion at a flow rate of $10 \mathrm{~mL}$ $\cdot \mathrm{kg}^{-1} \cdot \min ^{-1}$.

rhythm at approximately $34^{\circ} \mathrm{C}$, and mechanical ventilation was restarted. All animals were then rewarmed to $37^{\circ} \mathrm{C}$ by using a heat exchanger and an infrared heater and were slowly weaned from $\mathrm{CPB}$. After hemodynamic measurements, protamine was administered, and the CPB solution was removed. Autologous blood (collected before the operation) was then transfused. Finally, all the wounds were closed. The animals were kept connected to the ventilator throughout the procedure.

\section{Observation of Retinal Vessels}

Eye drops of atropine sulfate were applied preoperatively into the eyes of the animals. A fundus camera (Genesis; Kowa Co, Ltd, Nagoya, Japan) was used to take pictures of the retinas, including the retinal vessels. The diameters of the 3 major retinal arteries and those of the veins were measured at the edge of the retinal macula and were expressed as a ratio relative to the corresponding preoperative $\left(36^{\circ} \mathrm{C}\right)$ control values.

\section{Neurologic Assessment}

A postoperative neurologic assessment was performed in each animal by an independent observer. The modified neurologic deficit score (NDS) in $\operatorname{dogs}^{2-4}$ was used to evaluate neurologic deficits. The NDS evaluates 5 general components of the neurologic examination (central nerve function, respiration, motor and sensory function, level of consciousness, and behavior), with a score of 0 to 100 assigned to each category. A total score of 500 indicates the worst possible neurologic damage, whereas a score of 0 is normal. All the animals were closely evaluated for seizure activity. In this study, the "behavior" component of the NDS was modified to "abnormality" to enable the early postoperative condition to be evaluated (Table $1, A$ ).

\section{Tau Protein Levels in the CSF}

The CSF was sampled at several time points: before the operation, during $\mathrm{CPB}$ (rewarming), and 3, 6, and 12 hours after the operation. The samples were centrifuged and stored at $-80^{\circ} \mathrm{C}$ until analysis. The tau protein concentration, a marker of neuronal damage, was then measured with a commercially available enzyme-linked immunosorbent assay kit (Fino Scholar hTAU; Nipro, Osaka, Japan). The postoperative total tau protein level in each dog was calculated as the area under the curve (AUC) by using a trapezoidal method.

\section{Histopathologic Examination}

At 12 hours after the operation, the experiment was terminated, and the histopathologic studies were performed. The brains were quickly harvested immediately after the induction of cardiac arrest and after achievement of adequate anesthesia. The brains were then fixed with $7 \%$ buffered formaldehyde solution. Coronal sections (5-mm thick) of the brain were examined for gross lesions. Sections of interest were embedded in paraffin, cut to a thickness of $10 \mu \mathrm{m}$, stained with hematoxylin and eosin, and examined with light microscopy. Five anatomic areas (frontal lobe, parietal lobe, thalamus, hippocampus CA-1, and cerebellum) were examined by a pathologist who was unaware of the experimental groups. During the early period after the onset of hypoxic ischemic injury, the minimum criteria for the diagnosis of ischemic neuronal damage include mild cytoplasmic eosinophilia, shrunken neurons with scalloping of the margins, and nuclear changes consisting of coarse nuclear chromatin or pyknosis. ${ }^{5-8}$ A modified histopathologic damage score $(\mathrm{HDS})^{2}$ was used to determine the histopathologic damage. The HDS was defined as follows: no damaged neurons (0), minimal (2), mild (4), moderate (6), or severe (8).

\section{Statistical Analysis}

All data were presented as the mean \pm standard error of the mean. Data were assessed by using a 1-way analysis of variance for comparisons among the groups, followed by a post-hoc Dunnett test. The Spearman rank order correlation coefficient was used to correlate the 12-hour postoperative NDS and the total tau protein levels, as well as the NDS and HDSs and the total tau protein levels and HDS. All statistics were computed with the JMP analysis program, version 5.1 (SAS Institute Inc, Cary, NC).

\section{Results}

\section{Physiologic Variables}

There were no significant differences in the preoperative physiologic variables among the groups. The CSF pressure varied with the perfusion pressure of RCP. During RCP at the augmented pressure of $45 \mathrm{~mm} \mathrm{Hg}$, the CSF pressure became significantly higher in the RCP-INT group (32 \pm $4.0 \mathrm{~cm} \mathrm{CSF})$ than in the ASCP group $(14 \pm 1.9 \mathrm{~cm} \mathrm{CSF}$; $P<$.01, Dunnett post-hoc test). During RCP at the baseline pressure of $15 \mathrm{~mm} \mathrm{Hg}$, the CSF pressure was not signifi- 
Table 2. Physiologic variables

\begin{tabular}{|c|c|c|c|c|}
\hline & RCP-INT & ASCP & Sham & $P$ value \\
\hline Body weight (kg) & $28 \pm 1$ & $28 \pm 1$ & $29 \pm 1$ & .40 \\
\hline Sex (female/male ratio) & $3 / 3$ & $3 / 3$ & $3 / 3$ & 1.00 \\
\hline \multicolumn{5}{|l|}{$\mathrm{MAP}(\mathrm{mm} \mathrm{Hg})$} \\
\hline Preop & $121 \pm 12$ & $128 \pm 6$ & $133 \pm 9$ & .63 \\
\hline On CPB & $67 \pm 5$ & $69 \pm 5$ & $69 \pm 5$ & .85 \\
\hline Post3h & $99 \pm 5$ & $116 \pm 6$ & $103 \pm 7$ & .14 \\
\hline Post6h & $98 \pm 3$ & $122 \pm 12$ & $112 \pm 11$ & .21 \\
\hline Post12h & $81 \pm 9$ & $109 \pm 9$ & $98 \pm 15$ & .25 \\
\hline \multicolumn{5}{|l|}{ CSF pressure (cm CSF) } \\
\hline Preop & $17 \pm 0.6$ & $16 \pm 0.8$ & $17 \pm 0.9$ & .24 \\
\hline \multirow[t]{2}{*}{ During cerebral perfusion } & $19 \pm 0.7(15 \mathrm{~mm} \mathrm{Hg})$ & $15 \pm 1.6$ & $19 \pm 1.0$ & .06 \\
\hline & $32 \pm 4.0(45 \mathrm{~mm} \mathrm{Hg})$ & & & $.0007^{*}$ \\
\hline Post3h & $23 \pm 2.6$ & $24 \pm 5.4$ & $25 \pm 3.9$ & .94 \\
\hline Post6h & $24 \pm 5.0$ & $25 \pm 4.5$ & $27 \pm 4.3$ & .84 \\
\hline Post12h & $23 \pm 2.8$ & $23 \pm 2.3$ & $26 \pm 4.5$ & .83 \\
\hline \multicolumn{5}{|l|}{$\mathrm{PaO}_{2}(\mathrm{~mm} \mathrm{Hg})$} \\
\hline Preop & $349 \pm 24$ & $346 \pm 23$ & $429 \pm 56$ & .24 \\
\hline On CPB & $492 \pm 30$ & $533 \pm 37$ & $438 \pm 29$ & .20 \\
\hline Post3h & $304 \pm 95$ & $323 \pm 67$ & $379 \pm 91$ & .82 \\
\hline Post6h & $390 \pm 88$ & $373 \pm 82$ & $385 \pm 79$ & .98 \\
\hline Post12h & $400 \pm 79$ & $343 \pm 87$ & $378 \pm 68$ & .87 \\
\hline \multicolumn{5}{|l|}{$\mathrm{PaCO}_{2}(\mathrm{~mm} \mathrm{Hg})$} \\
\hline Preop & $34 \pm 1$ & $30 \pm 2$ & $34 \pm 2$ & .29 \\
\hline On CPB & $42 \pm 4$ & $40 \pm 2$ & $38 \pm 2$ & .72 \\
\hline Post3h & $40 \pm 5$ & $40 \pm 6$ & $48 \pm 3$ & .28 \\
\hline Post6h & $40 \pm 5$ & $37 \pm 6$ & $50 \pm 3$ & .16 \\
\hline Post12h & $38 \pm 3$ & $37 \pm 6$ & $47 \pm 6$ & .3 \\
\hline \multicolumn{5}{|l|}{ Arterial pH } \\
\hline Preop & $7.38 \pm 0.04$ & $7.40 \pm 0.02$ & $7.43 \pm 0.02$ & .54 \\
\hline On CPB & $7.24 \pm 0.06$ & $7.28 \pm 0.04$ & $7.37 \pm 0.03$ & .11 \\
\hline Post3h & $7.32 \pm 0.04$ & $7.42 \pm 0.07$ & $7.32 \pm 0.01$ & .26 \\
\hline Post6h & $7.36 \pm 0.05$ & $7.44 \pm 0.06$ & $7.29 \pm 0.02$ & .13 \\
\hline Post12h & $7.36 \pm 0.03$ & $7.41 \pm 0.06$ & $7.31 \pm 0.04$ & .33 \\
\hline \multicolumn{5}{|l|}{$\mathrm{SvO}_{2}(\%)$} \\
\hline Preop & $82 \pm 4$ & $86 \pm 4$ & $87 \pm 5$ & .74 \\
\hline On CPB & $86 \pm 5$ & $86 \pm 3$ & $85 \pm 5$ & .97 \\
\hline Post3h & $76 \pm 8$ & $71 \pm 5$ & $71 \pm 6$ & .81 \\
\hline Post6h & $72 \pm 7$ & $65 \pm 7$ & $68 \pm 7$ & .80 \\
\hline Post12h & $69 \pm 10$ & $72 \pm 5$ & $69 \pm 6$ & .94 \\
\hline \multicolumn{5}{|l|}{ Hemoglobin (g/dL) } \\
\hline Preop & $13.0 \pm 0.4$ & $13.5 \pm 1.0$ & $12.0 \pm 0.8$ & .31 \\
\hline On CPB & $5.5 \pm 0.3$ & $5.5 \pm 0.3$ & $5.0 \pm 0.3$ & .33 \\
\hline Post3h & $12.0 \pm 0.4$ & $12.3 \pm 0.7$ & $11.0 \pm 0.7$ & .20 \\
\hline Post6h & $11.0 \pm 0.9$ & $11.0 \pm 0.9$ & $11.3 \pm 0.9$ & .86 \\
\hline Post12h & $11.4 \pm 1.0$ & $10.8 \pm 0.9$ & $11.7 \pm 0.9$ & .81 \\
\hline
\end{tabular}

RCP-INT, Intermittent-retrograde cerebral perfusion at $15 \mathrm{~mm} \mathrm{Hg}$ with intermittent pressure augmentation to $45 \mathrm{~mm} \mathrm{Hg}$; $A S C P$, antegrade selective cerebral perfusion at a flow rate of $10 \mathrm{~mL} \cdot \mathrm{kg}^{-1} \cdot \mathrm{min}^{-1} ; M A P$, mean arterial pressure; preop, preoperative; $C P B$, cardiopulmonary bypass; post3h, 3 hours after the operation; post6h, 6 hours after the operation; post12h, 12 hours after the operation; $C S F$, cerebrospinal fluid; $S v 0_{2}$, mixed venous saturation of oxygen. ${ }^{*} P<.05$.

cantly different among the groups $(P=.06)$, although the ASCP group tended to show lower CSF pressures. No other parameters were significantly different among the groups (Table 2).

\section{Retinal Vessels}

In the RCP-INT group the retinal vessels were effectively dilated at an augmented pressure of $45 \mathrm{~mm} \mathrm{Hg}$ (arteries, $107 \% \pm 3 \%$ of control, $P=.041$; veins, $114 \% \pm 3 \%$ of 

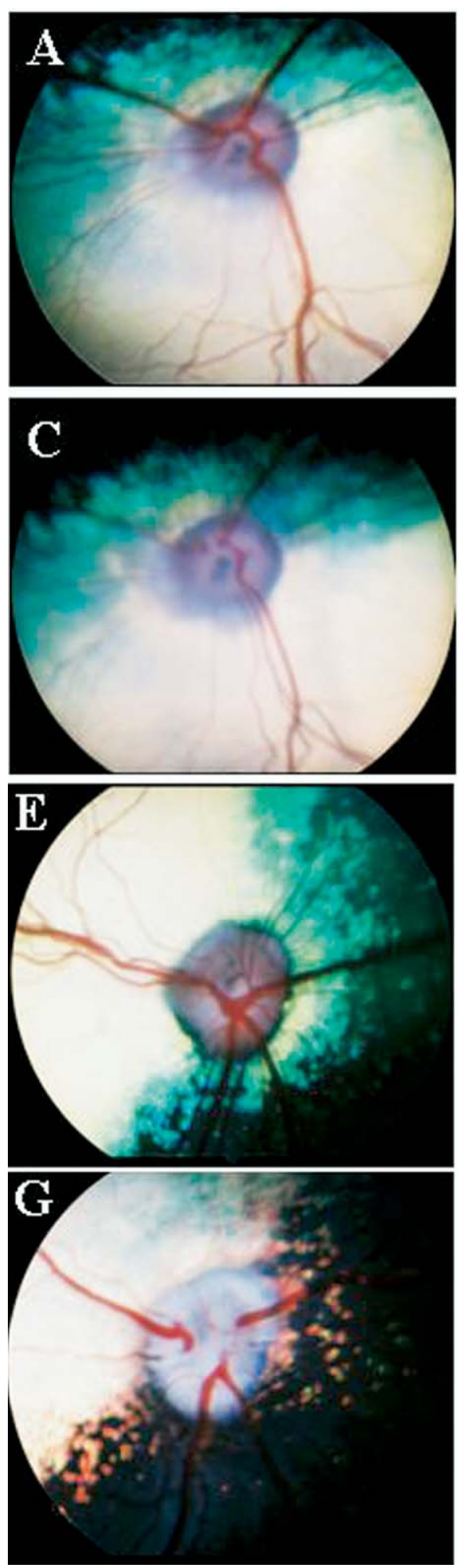
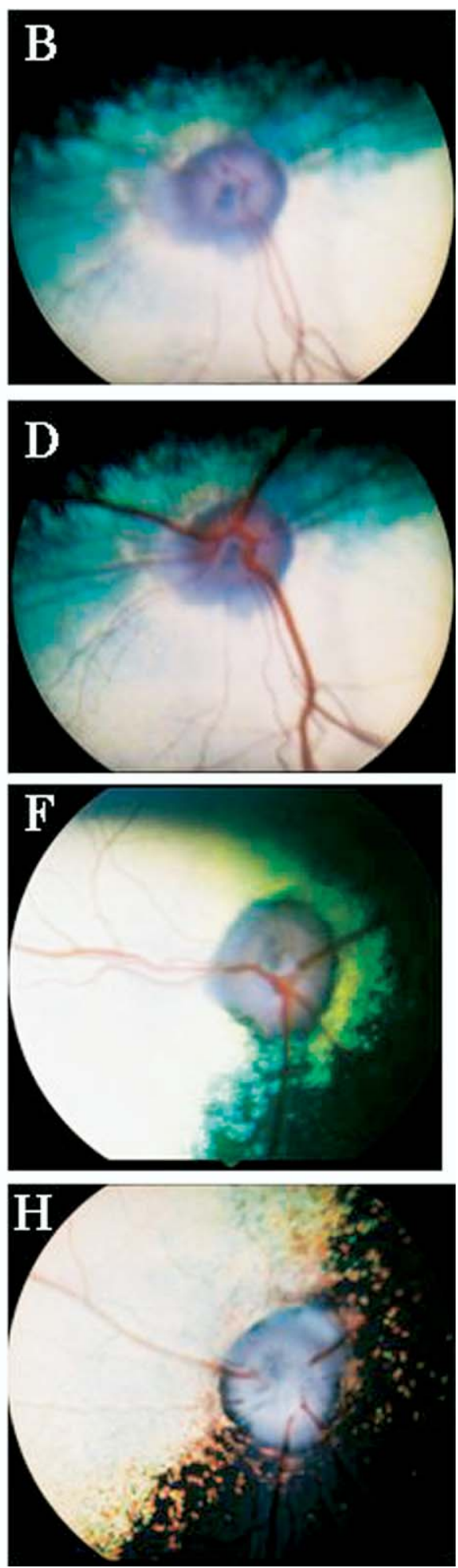

Figure 1. Fundus photography. Panels $A$ through $D$ are from the intermittent-retrograde cerebral perfusion at $15 \mathrm{~mm} \mathrm{Hg}$ with intermittent pressure augmentation to $45 \mathrm{~mm} \mathrm{Hg}$ (RCP-INT) group. Panels $E$ and $F$ are from the antegrade selective cerebral perfusion at a flow rate of $10 \mathrm{~mL} \cdot \mathrm{kg}^{-1} \cdot \mathrm{min}^{-1}$ (ASCP) group. Panels $\mathrm{G}$ and $\mathrm{H}$ are from the sham group. $\mathrm{A}$, E, and G, Before CPB at $36^{\circ} \mathrm{C} ; \mathrm{B}, 15 \mathrm{~mm} \mathrm{Hg}$ of $\mathrm{RCP}$ at $26^{\circ} \mathrm{C}$; C, RCP at $25 \mathrm{~mm} \mathrm{Hg}$ at $26^{\circ} \mathrm{C}$; D, RCP at $45 \mathrm{~mm} \mathrm{Hg}$ at $26^{\circ} \mathrm{C}$; $\mathrm{F}$, during antegrade selective cerebral perfusion at $26^{\circ} \mathrm{C}$; and $\mathrm{H}$, during cardiopulmonary bypass at $26^{\circ} \mathrm{C}$ without circulatory arrest. 

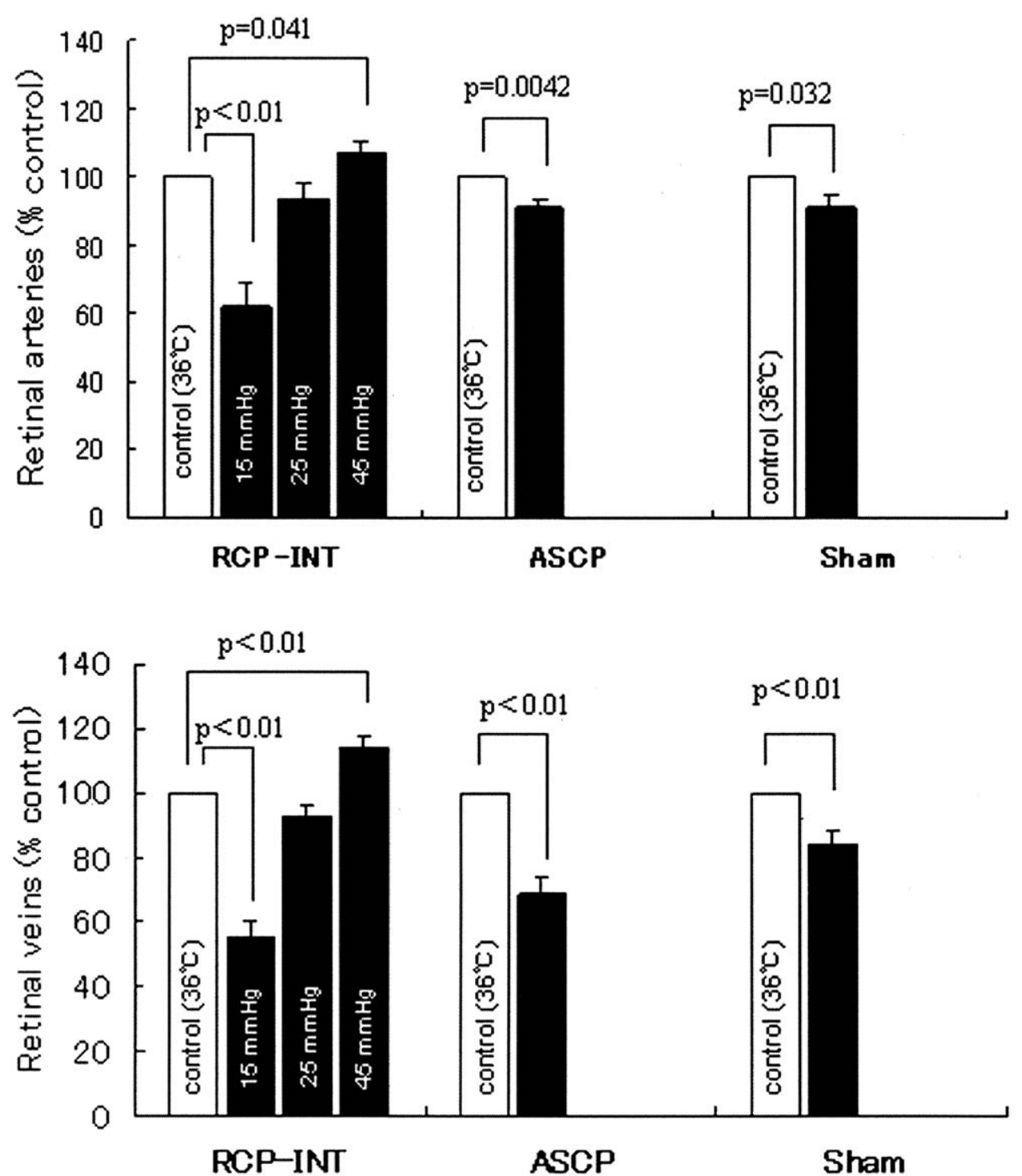

Figure 2. Diameters of the retinal arteries and veins in the intermittent-retrograde cerebral perfusion at $15 \mathrm{~mm} \mathrm{Hg}$ with intermittent pressure augmentation to $45 \mathrm{~mm}$ $\mathrm{Hg}$ (RCP-INT), antegrade selective cerebral perfusion at a flow rate of $10 \mathrm{~mL} \cdot \mathrm{kg}^{-1} \cdot \mathrm{min}^{-1}$ (ASCP), and sham groups. Values for the retinal arteries and veins are expressed as ratios relative to the corresponding preoperative $\left(36^{\circ} \mathrm{C}\right)$ control values. control, $P<.01$ ). In the RCP-INT (perfusion pressure of 15 $\mathrm{mm} \mathrm{Hg}$ ), ASCP, and sham groups the retinal vessels at $26^{\circ} \mathrm{C}$ were smaller than the corresponding preoperative $\left(36^{\circ} \mathrm{C}\right)$ vessels (Figures 1 and 2).

\section{Neurologic Assessment}

The final total NDS at 12 hours after the operation did not differ significantly among the groups (RCP-INT, $75 \pm 21$; ASCP, $70 \pm 21$; sham, $57 \pm 23 ; P=.83$; ASCP vs RCP-INT, $P=.98$, Dunnett post-hoc test). For each neurologic component, no significant differences were observed among the groups (Table 1,B).

\section{Tau Protein Levels in the CSF}

No significant differences in the tau protein concentrations before the operation were seen among the groups (RCP-INT,
$44 \pm 9 \mathrm{pg} / \mathrm{mL} ;$ ASCP, $19 \pm 9 \mathrm{pg} / \mathrm{mL}$; sham, $25 \pm 13$ $\mathrm{pg} / \mathrm{mL} ; P=.23)$. The tau protein levels did not differ significantly among the groups during CPB (RCP-INT, $11 \pm 5 \mathrm{pg} / \mathrm{mL}$; ASCP, $2 \pm 2 \mathrm{pg} / \mathrm{mL}$; sham, $19 \pm 9 \mathrm{pg} / \mathrm{mL}$; $P=.18$ ) or at 3 hours (RCP-INT, $2 \pm 2 \mathrm{pg} / \mathrm{mL}$; ASCP, $10 \pm 4 \mathrm{pg} / \mathrm{mL}$; sham, $6 \pm 3 \mathrm{pg} / \mathrm{mL} ; P=.33$ ), 6 hours (RCP-INT, $9 \pm 5 \mathrm{pg} / \mathrm{mL}$; ASCP, $19 \pm 12 \mathrm{pg} / \mathrm{mL}$; sham, $1 \pm 1 \mathrm{pg} / \mathrm{mL} ; P=.24$ ), and 12 hours (RCP-INT, $46 \pm 23$ $\mathrm{pg} / \mathrm{mL} ;$ ASCP, $13 \pm 10 \mathrm{pg} / \mathrm{mL}$; sham, $67 \pm 62 \mathrm{pg} / \mathrm{mL} ; P=$ .62) after the operation. The total tau protein levels after the operation (AUC value over 12 hours) also were not significantly different among the groups (RCP-INT, $203 \pm$ $87 \mathrm{pg} \cdot \mathrm{mL}^{-1} \cdot \mathrm{h}$; ASCP, $154 \pm 69 \mathrm{pg} \cdot \mathrm{mL}^{-1} \cdot \mathrm{h}$; sham, $250 \pm 197 \mathrm{pg} \cdot \mathrm{mL}^{-1} \cdot \mathrm{h} ; P=.87$; ASCP vs RCP-INT, $P=.95$, Dunnett post-hoc test; Figure 3). A significant correlation between the final total NDS and the 


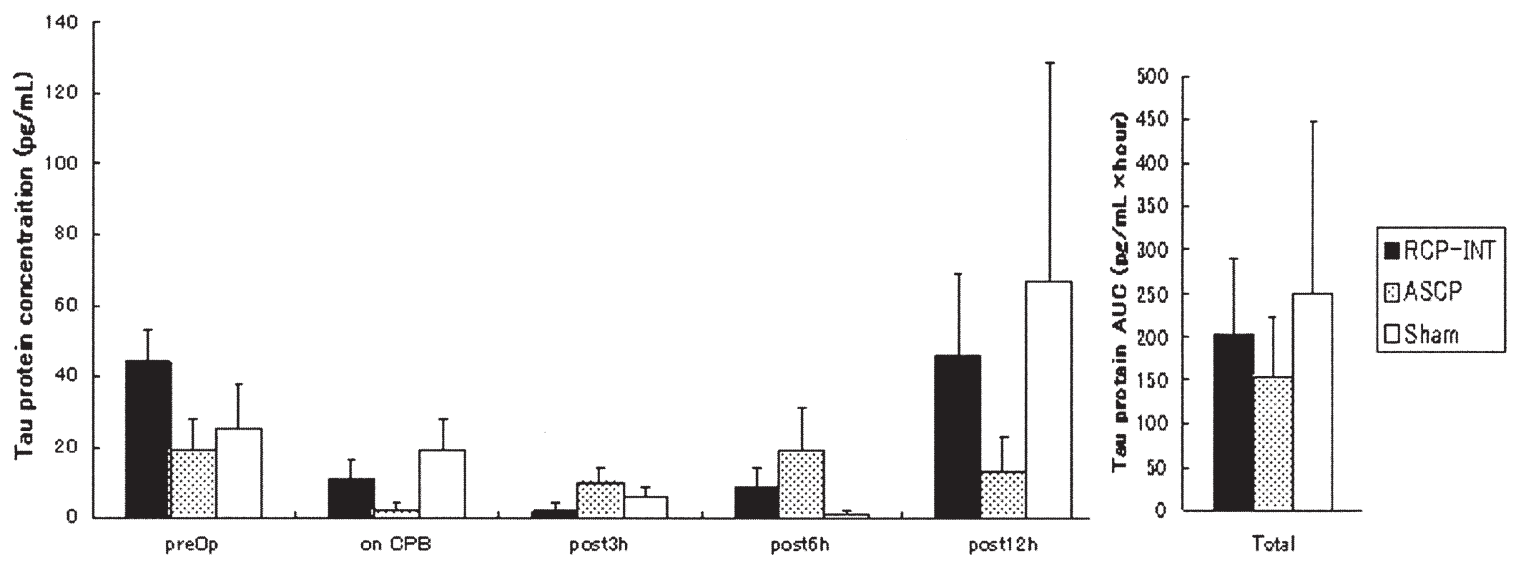

Figure 3. Tau protein levels in the cerebrospinal fluid (CSF). RCP-INT, Intermittent-retrograde cerebral perfusion at $15 \mathrm{~mm} \mathrm{Hg}$ with intermittent pressure augmentation to $45 \mathrm{~mm} \mathrm{Hg}$; $A S C P$, antegrade selective cerebral perfusion at a flow rate of $10 \mathrm{~mL} \cdot \mathrm{kg}^{-1} \cdot \mathrm{min}^{-1}$; preop, preoperative; post6h, 6 hours after the operation; post12h, 12 hours after the operation. No significant differences in the tau protein levels were seen among the groups.

total tau protein level was seen (Spearman correlation coefficient $=0.8349, P<.0001)$.

\section{Histopathologic Examination}

No macroscopic gross lesions were observed in any of the brain specimens. The total HDS did not differ significantly among the groups (RCP-INT, $14 \pm 1.3$; ASCP, $13 \pm 1.5$; sham, $13 \pm 2.1 ; P=.77$; ASCP vs RCP-INT, $P=.84$, Dunnett post-hoc test). The regional HDSs for the 5 selected anatomic areas did not differ significantly among the groups (Figure 4). A significant correlation was observed between the final total NDS and the total HDS (Spearman correlation coefficient $=0.7498, P=.0003$ ). A significant correlation between the total tau protein levels and the total HDS was also observed (Spearman correlation coefficient $=0.7973$, $P<$.0001). Samples from all the groups showed only minimal evidence of cellular change and no evidence of either cerebral edema or hemorrhage (Figure 5).

\section{Discussion}

Higher RCP pressure methods ${ }^{9,10}$ and intermittent RCP methods ${ }^{11,12}$ have also been reported, with good outcomes

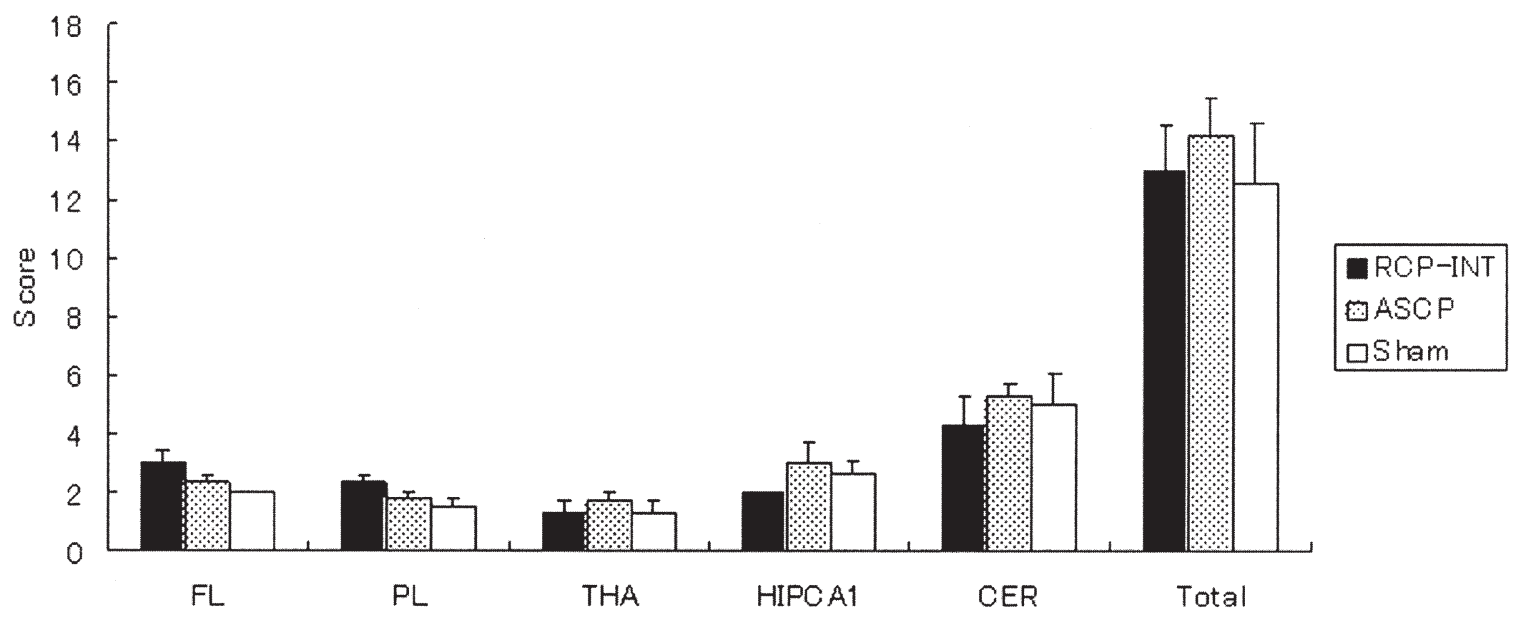

Figure 4. Histopathologic damage score. RCP-INT, Intermittent-retrograde cerebral perfusion at $15 \mathrm{~mm} \mathrm{Hg}$ with intermittent pressure augmentation to $45 \mathrm{~mm} \mathrm{Hg}$; $A S C P$, antegrade selective cerebral perfusion at a flow rate of 10 $\mathrm{mL} \cdot \mathrm{kg}^{-1} \cdot \min ^{-1} ; \mathrm{FL}$, frontal lobe; PL, parietal lobe; THA, thalamus; HIPCA1, hippocampus CA1 area; CER, cerebellum; Total, total histopathologic damage score. No significant differences in the histopathologic damage score were seen among the groups. 

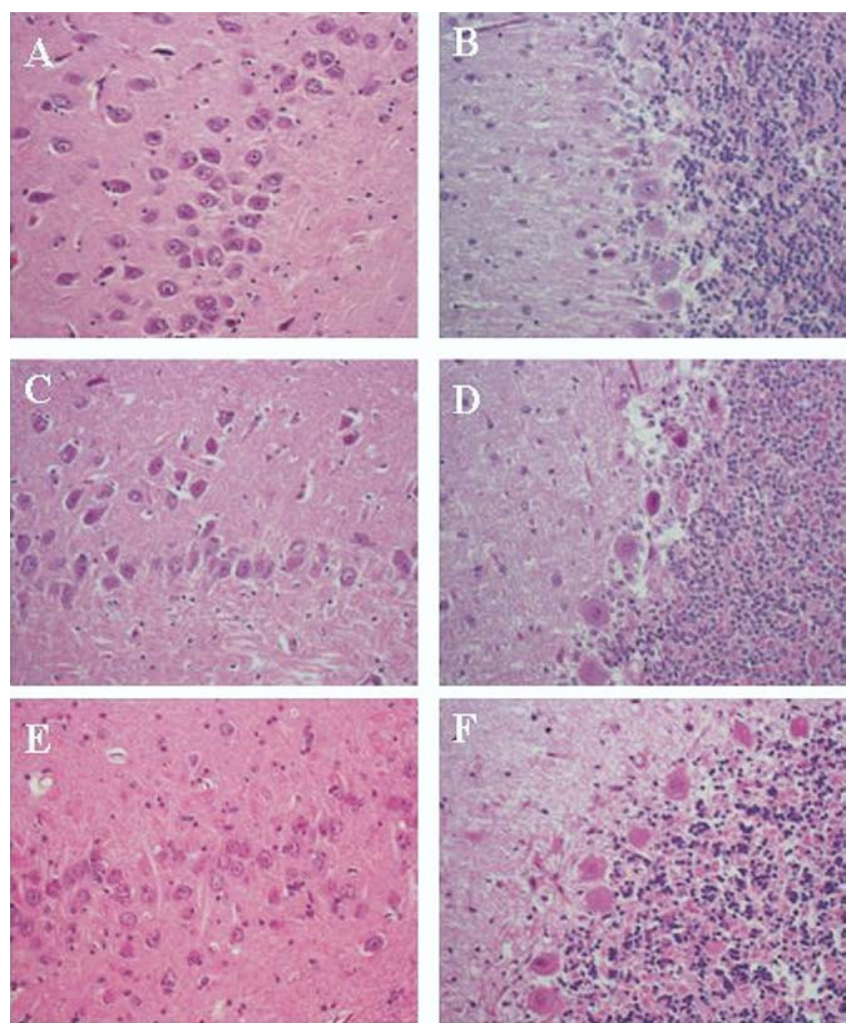

Figure 5. Histopathologic examination. Panels A, C, and E are sections of the hippocampus CA1 area. (Hematoxylin and eosin; original magnification $200 \times$.) Panels $B, D$, and $F$ are sections of the cerebellum. (Hematoxylin and eosin, original magnification $200 \times$ ). Panels A and B are from the intermittent-retrograde cerebral perfusion at $15 \mathrm{~mm} \mathrm{Hg}$ with intermittent pressure augmentation to $45 \mathrm{~mm} \mathrm{Hg}$ (RCP-INT) group. Panels C and D are from the antegrade selective cerebral perfusion at a flow rate of $10 \mathrm{~mL}$. $\mathrm{kg}^{-1} \cdot \min ^{-1}$ (ASCP) group. Panels $E$ and $F$ are from the sham group. All of the sections show only minimal evidence of cellular change and no evidence of either cerebral edema or hemorrhage.

and no significant complications. $\mathrm{Li}$ and colleagues ${ }^{9}$ reported that higher RCP pressures (34-40 $\mathrm{mm} \mathrm{Hg}$ ) amplified cerebral tissue perfusion and tissue oxygenation, without increasing tissue edema. Estrera and associates ${ }^{10}$ showed that the mean RCP peak pressure for identifying cerebral blood flow was $31.8 \pm 9.7 \mathrm{~mm} \mathrm{Hg}$. Although they examined the application of high RCP pressures, they did not observe evidence of increased cerebral edema. A high RCP pressure of approximately 40 to $50 \mathrm{~mm} \mathrm{Hg}$ is thought to be needed to overcome the threshold for the dilation of cerebral microvessels during hypothermia. By applying this high pressure intermittently, we hoped to prevent the cerebral edema that is caused by a continuous high RCP pressure. The present study showed no evidence of increased cerebral edema in the RCP-INT group.
The cerebral blood flow autoregulation is not significant under conditions of hypothermia. A body temperature of $26^{\circ} \mathrm{C}$, cardiac arrest, and circulatory arrest to half of the body are nonphysiologic situations for living animals. Therefore we think that control of artificial cerebral perfusion is needed.

The blood returned to the aortic arch through the cerebral vessels in the RCP-INT group was obviously venous dark blood, in which the oxygen saturation was significantly lower than that in the perfused oxygenated blood. The returned blood volume to the aortic arch in the RCP-INT group was about $60 \%$ to $80 \%$ of the volume of the perfused oxygenated blood.

Observation of the retinal vessels is a direct, sensitive, and noninvasive method for observing cerebral blood flow and assessing the effects of cerebral perfusion. ${ }^{1,13-15} \mathrm{We}$ concluded that dilatation of the retinal vessels in the RCPINT group was reflective of adequate cerebral flow because we also observed the blood passing through the retinal veins and capillary vessels to the retinal arteries using a fundus camera. A similar conclusion was also drawn by Ono and coworkers ${ }^{14}$ in conventional RCP. We monitored not only the vascular dilatation but also observed the blood passing through the vessels. During hypothermia, all the groups showed vasoconstriction of the retinal vessels (RCP-INT [15 mm Hg], ASCP, and sham). However, during RCP-INT (25 $\mathrm{mm} \mathrm{Hg}$ ), no significant differences were observed from the corresponding preoperative condition $\left(36^{\circ} \mathrm{C}\right)$. We thought that this result was due to the gradual opening up of the blood vessels during the intermittent pressure augmentation to $45 \mathrm{~mm} \mathrm{Hg}$. We confirmed similar vasoconstriction of the retinal blood vessels in the conventional $\mathrm{RCP}$ (fixed perfusion pressure of $25 \mathrm{~mm} \mathrm{Hg}$ ) group as in the ASCP and sham groups. On the other hand, significant vascular opening was observed in the RCP-INT $(45 \mathrm{~mm}$ $\mathrm{Hg}$ ) group compared with that seen in the other groups.

Only minimal evidence of acute ischemic neuronal cell changes was seen in all the groups. This suggests that RCP-INT and ASCP during moderate hypothermia provided a similar extent of protection against acute ischemic neuronal cell changes. During RCP at an augmented pressure of $45 \mathrm{~mm} \mathrm{Hg}$, the CSF pressure was significantly higher in the RCP-INT group than in the ASCP group. However, the CSF pressure was not significantly different among the groups when a baseline pressure of $15 \mathrm{~mm} \mathrm{Hg}$ was applied during RCP. Therefore cerebral edema was not observed in the RCP-INT group.

Tau protein level in the CSF is considered a good biomarker of neuronal damage. ${ }^{16-20}$ We believe that the results of tau protein levels would have been the same even after 24 or 48 hours because the tau protein levels in the CSF in individual cases did not show any steady increase in all groups. Some cases remained steady, and other cases 
showed a peak out pattern. Therefore we compared the total tau protein levels by using AUC. The total tau protein levels showed no significant differences among the groups.

Although some authors have questioned the validity of the neurologic protection provided by $\mathrm{RCP},{ }^{6,21}$ this study showed that our modification of the RCP technique produced a satisfactory neuroprotective outcome equivalent to that provided by ASCP.

\section{Study Limitations}

If the dogs had been observed for a longer period of time, such as 1 week or more, a greater difference in functional outcome might have been seen. However, allowing longterm survival of brain-damaged and laminectomized animals is neither feasible nor humane. Therefore we decided to limit our postoperative observations to a 12 -hour period. We used moderate hypothermia of $26^{\circ} \mathrm{C}$ for 60 minutes in this study. Additional studies under different conditions are necessary.

\section{Conclusion}

This study showed that intermittent pressure augmentation during RCP efficiently dilated the cerebral vessels, allowing an adequate blood supply without injuring the brain. This RCP-INT during moderate hypothermia provides adequate neuroprotection equivalent to that provided by ASCP.

We thank Mr Nobutaka Furuya and Mr Takashi Kubota for their technical assistance. We also thank the Department of Pathology, Graduate School of Medicine, University of Tokyo, for their technical assistance and help with the histopathologic evaluation.

\section{References}

1. Kitahori K, Takamoto S, Takayama H, Suematsu Y, Ono M, Motomura N, et al. A novel protocol of retrograde cerebral perfusion with intermittent pressure augmentation for brain protection. J Thorac Cardiovasc Surg. 2005;130:363-70.

2. Safer P, Xiao F, Radovsky A, Tanigawa K, Ebmeyer U, Bircher N, et al. Improved cerebral resuscitation from cardiac arrest in dogs with mild hypothermia plus blood flow promotion. Stroke. 1996;27:105-13.

3. Tisherman SA, Safar P, Radovsky A, Peitzman A, Marrone G, Kuboyama K, et al. Profound hypothermia (less than 10 degrees C) compared with deep hypothermia (15 degrees $\mathrm{C}$ ) improves neurologic outcome in dogs after two hours circulatory arrest induced to enable resuscitative surgery. J Trauma. 1991;31:1051-62.

4. Castella M, Buckberg GD, Tan Z. Neurologic Preservation by $\mathrm{Na}+-\mathrm{H}+$ exchange inhibition prior to 90 minutes of hypothermic circulatory arrest. Ann Thorac Surg. 2005;79:646-54.
5. Ye J, Yang L, Del Bigio MR, Filgueriras CL, Ede M, Summers R, et al. Neuronal damage after hypothermic circulatory arrest and retrograde cerebral perfusion in the pig. Ann Thorac Surg. 1996;61:1316-22.

6. Ye J, Ryner LN, Kozlowski P, Yang L, Del Bigio MR, Sun J, et al. Retrograde cerebral perfusion results in flow distribution abnormalities and neuronal damage. A magnetic resonance imaging and histopathological study in pigs. Circulation. 1998;98(suppl II):II313-8.

7. Weller RO. General pathology of neurons: In: Symmers WSC, editor. Systemic pathology. Vol. 4, Nervous system, muscle and eyes. 3rd ed. New York: Churchill Livingstone; 1990. p. 38-40.

8. Frosch MP, Anthony DC, Girolami UD. The central nervous system. In: Kumar V, Abbas AK, Fausto N, editors. Robins and Cotran pathologic basis of disease. 7th ed. Philadelphia: Elsevier Saunders; 2005. p. 1347-63.

9. Li Z, Yang L, Jackson M, Summers R, Donnelly M, Deslauriers R, et al. Increased pressure during retrograde cerebral perfusion in an acute porcine model improves brain tissue perfusion without increase in tissue edema. Ann Thorac Surg. 2002;73:1514-21.

10. Estrera AL, Grami A, Miller CC 3rd, Sheinbaum R, Huynh TT, Porat EE, et al. Determination of cerebral blood flow dynamics during retrograde cerebral perfusion using power M-mode transcranial Doppler. Ann Thorac Surg. 2003;76:704-10.

11. Anttila V, Pokela M, Kiviluoma K, Rimpilainen J, Vainoionpaa V, Hirvonen $\mathrm{J}$, et al. Intermittent retrograde cerebral perfusion during prolonged period of hypothermic circulatory arrest. A study in a chronic porcine model. Scand Cardiovasc J. 2000;34:116-23.

12. Nojima T, Mori A, Watarida S, Onoe M. Cerebral metabolism and effects of pulsatile flow during retrograde cerebral perfusion. $J$ Cardiovasc Surg. 1993;34:483-92.

13. Dong P, Guan Y, Yang J, He M, Wan C. Fundus microvascular flow monitoring during retrograde cerebral perfusion: an experimental study. Ann Thorac Surg. 2000;70:1478-82.

14. Ono T, Okita Y, Ando M, Kitamura S. Retrograde cerebral perfusion in human brains. Lancet. 2000;356:1323.

15. Ono T. Fluorescein retinal angiography as a useful method of observing cerebral perfusion during aortic arch surgery. Ann Thorac Surg. 2001;72:978-9.

16. Zemlan FP, Jauch EC, Mulchahey JJ, Gabbita SP, Rosenberg WS, Speciale SG, et al. C-tau biomarker of neuronal damage in severe brain injured patients: association with elevated intracranial pressure and clinical outcome. Brain Res. 2002;947:131-9.

17. Shiiya N, Kunihara T, Miyatake T, Matsuzaki K, Yasuda K. Tau protein in the cerebrospinal fluid is a marker of brain injury after aortic surgery. Ann Thorac Surg. 2004;77:2034-8.

18. Chatfield DA, Zemlan FP, Day DJ, Menon DK. Discordant temporal patterns of $S 100 \beta$ and cleaved tau protein elevation after head injury: a pilot study. Br J Neurosurg. 2002;16:471-6.

19. Bitsch A, Horn C, Kemmling Y, Seipelt M, Hellenbrand U, Stiefel M, et al. Serum tau protein level as a marker of axonal damage in acute ischemic stroke. Eur Neurol. 2002;47:45-51.

20. Zemlan FP, Rosenberg WS, Luebbe PA, Campbell TA, Dean GE, Weiner NE, et al. Quantification of axonal damage in traumatic brain injury: affinity purification and characterization of cerebrospinal fluid tau proteins. J Neurochem. 1999;72:741-50.

21. Ehrlich MP, Hagl C, McCullough JN, Zhang N, Shiang H, Bodian C, et al. Retrograde cerebral perfusion provides negligible flow through brain capillaries in the pig. J Thorac Cardiovasc Surg. 2001;122: $331-8$. 